\title{
O tempo é o mesmo para todos? Um estudo sobre percepções temporais com jovens trabalhadores de São Paulo (SP) e Curitiba (CR)
}

\section{Is time the same for everyone? A study on temporal perceptions with young workers from São Paulo (SP) and Curitiba (CR)}

\author{
Jane Kelly Dantas Barbosa \\ FACE-UFMG \\ jane_kdantas@hotmail.com \\ Samara de Menezes Lara \\ UFV-Florestal \\ mgsamaralara@gmail.com \\ Kely César Martins de Paiva \\ FACE-UFMG \\ kelypaiva@ face.ufmg.br
}

Submissão: $26 / 03 / 2019$

Aprovação: $12 / 03 / 2020$

\begin{abstract}
RESUMO
Diante dos modos de viver contemporâneos, nos quais o tempo é considerado um bem cada vez mais escasso, difícil de entender e de administrar, a maneira com a qual as pessoas lidam com o seu tempo e as suas demandas pessoais e profissionais pode trazer reflexos para o contexto organizacional e para o indivíduo. No caso dos jovens trabalhadores, público marcado por idiossincrasias e dificuldades no mundo laboral, as preferências e estratégias para lidar com o tempo em suas atividades podem impactar o seu desempenho e o desempenho da organização onde se inserem. Dado isto, o objetivo deste trabalho consiste em analisar e comparar como se configuram as percepções temporais de jovens trabalhadores assistidos pelo ESPRO das cidades de São Paulo (SP) e Curitiba (PR). Realizou-se um estudo de caso com pesquisa de campo, quantitativa e descritiva. A coleta de dados foi feita por meio de questionários e eles foram tratados a partir de análise estatística descritiva uni e bivariada. Percebeu-se certa consonância entre os achados de São Paulo (SP) e de Curitiba (PR) no que diz respeito à velocidade, pontualidade e arrastamento. Por outro lado, há discrepâncias consideráveis quanto à policronicidade e à profundidade temporal dos jovens, mostrando que o tempo é percebido e vivenciado de modo diferente pelos grupos abordados.
\end{abstract}

Palavras-chave: tempo, percepções temporais, jovens trabalhadores. 


\begin{abstract}
In front of contemporary ways of living, where time is considered an increasingly scarce, hard to understand and manage, the way in which people deal with their time and their personal and professional demands can bring the organizational context and the individual. In case of young workers, public marked by idiosyncrasies and difficulties in work's scene, preferences and strategies to deal with time in their activities can impact their performance and the performance of the organization where they are. Given this, the objective of this work is to analyze and compare how the temporal perceptions of young workers assisted by ESPRO in the cities of São Paulo (SP) and Curitiba (PR) are configured. A case study was carried out with field research, quantitative and descriptive. Data collection was done through questionnaires and they were treated from univariate and bivariate descriptive statistical analysis. There was a certain consonance between the findings of São Paulo (SP) and Curitiba (PR) regarding speed, punctuality and entrainment. In other side, there are considerable discrepancies regarding the polychronicity and temporal depth of the young, showing that time is perceived and experienced differently by the groups addressed.
\end{abstract}

Keywords: time, temporal perceptions, young workers.

\title{
1 Introdução
}

Dizemos que o tempo é o melhor remédio, é o senhor da razão, é dinheiro, que ele não para, que não temos tempo a perder... Mas, o que é o tempo? Nós construímos o tempo ou o tempo nos constrói? O tempo passa por nós ou nós passamos por ele? Existiria uma concepção de tempo comum a todos ou o tempo varia conforme pessoas, grupos, organizações, culturas e países? A partir do momento em que a humanidade passou a ter consciência do tempo e, posteriormente, passou a mensurá-lo, sua concepção e relação com ele foi se alterando.

Antes encarado como algo linear, o tempo passou a ser visto como algo cheio de bifurcações e dimensões, algo irregular, com uma velocidade que ocasiona regimes temporais incertos e instáveis (GRISCI, 1999). A compressão do tempo e do espaço implica na representação de um tempo de insegurança, no qual as tradições e o passado foram paulatinamente abandonados e o futuro é visto como imediato e incerto. A mensuração antes mais sólida transformou-se em algo líquido, fluido, num tempo em que as pessoas precisam se manter no ritmo ditado por outrem para não se perderem, o que significa "mudar o guardaroupa, a mobília, o papel de parede, a aparência, os hábitos - em suma, você mesmo - tão frequentemente quanto consiga" (BAUMAN, 2007, p. 108).

Essa realidade encontra-se vinculada ao discurso globalizante, da modernidade, da mudança incessante, da necessidade de adoção de características de pessoas multifuncionais e dinâmicas. Nesse contexto, as maneiras de lidar com o tempo sofreram grandes transformações, incluindo avanços nos estudos sobre o tema, embora seja comum o sentimento contraditório de que quanto mais avançam os esforços para compreensão e controle sobre o tempo, mais parece que os indivíduos são escravizados por ele (MELLO; TONELLI, 2002b). Na sociedade contemporânea, o tempo é visto por muitos como uma mercadoria e envolve um senso de urgência que dita o ritmo do cotidiano das pessoas, tornando a aceleração e a velocidade comuns no ambiente de trabalho e nas demais esferas da vida (TONELLI, 2008).

Discorrendo sobre o tema, Bluedorn e Jaussi (2007) chamam atenção às diferentes percepções que os sujeitos podem ter acerca do tempo para lidar com a vida e o trabalho. Os 
autores elencam cinco dimensões temporais, a saber: policronicidade, velocidade, pontualidade, profundidade temporal, e, por fim, arrastamento. A forma como o sujeito lida com essas dimensões temporais pode afetar o relacionamento entre os profissionais, tanto em relação à duração quanto a qualidade desses relacionamentos, além de trazer possíveis impactos em atitudes e crenças sobre si mesmos (BLUEDORN; JAUSSI, 2007). Sendo assim, torna-se importante compreender a heterogeneidade que envolve as formas de se situar em relação ao tempo, as suas implicações em termos de adequação (maior ou menor) do sujeito ao tipo de trabalho a ser realizado e em termos de constituição de suas vivências laborais.

Entender como os indivíduos lidam com o tempo na vida e no trabalho se faz relevante, uma vez que ele constitui uma dimensão que atravessa todas as vivências humanas. No caso específico de pessoas mais jovens, a forma com que percebem e lidam com o tempo pode estar relacionada às dificuldades pelas quais elas passam nessa fase da vida em que transitam entre a leveza da infância e as responsabilidades da vida adulta (TOMÁS; OLIVEIRA; RIOS-NETO, 2008) e, ainda, às dificuldades que enfrentam em relação ao mundo laboral (REIS, 2015; VERIGUINE; BASSO; SOARES, 2014).

Os jovens trabalhadores podem ser entendidos como os trabalhadores na faixa etária de 15 a 24 anos (UNFPA, 2010), caracterizados por peculiaridades (POCHMANN, 1998; PAIVA, 2016) e pelo fato de que usualmente se inserem em contextos trabalhistas marcados por incerteza, precariedade e informalidade (LOUGHLIN; LANG, 2005; TUCKER; LOUGHLIN, 2006; BOTELHO, 2016), realizando tarefas de natureza empobrecida e de cunho rotineiro e repetitivo (PAIVA; SOUZA, 2016).

Conforme dados da Organização das Nações Unidas (ONU), a juventude brasileira está em segundo lugar no ranking de pessimismo em relação ao trabalho (WICKERT, 2006). Os aspectos econômicos e sociais podem tornar o contexto de transição para o trabalho mais difícil, considerando que os jovens situados em grupos mais vulneráveis enfrentam ainda mais dificuldades. Questões como gênero, raça, classe social, local de moradia e acesso à escolaridade representam aspectos preocupantes que impactam essa transição (UNFPA, 2010; VENTURI; TORINI, 2014; MESQUITA; JÚNIOR; SIMÕES, 2012).

Dessa forma, torna-se relevante realizar estudos envolvendo jovens em situações de vulnerabilidade social e sua relação com o mundo do trabalho, como é o caso dos jovens atendidos pela Associação de Ensino Social Profissionalizante, o ESPRO. O ESPRO é uma instituição reconhecida pelo Ministério do Trabalho e Previdência Social, que atua em quatro eixos: Programa Jovem Aprendiz e Estágio, Programa Formação para o Mundo do Trabalho, Oficinas de Arte e Cultura e Desenvolvimento Social. A instituição defende que "a educação e a assistência social são a base do desenvolvimento integral do ser humano" (Relatório de Atividades Anual ESPRO, 2015, p. 60) e, dos jovens atendidos, 47\% são considerados em situação de alta vulnerabilidade social e $35 \%$ em situação de altíssima vulnerabilidade social, enquanto em situação de média e baixa vulnerabilidade estão $16 \%$ e $2 \%$, respectivamente (Relatório de Atividades Anual ESPRO, 2015). Tal categorização de vulnerabilidade social é feita considerando os seguintes aspectos: 1) tipo, classificação e condições da moradia; 2) composição familiar; 3) rendas e despesas da família; 4) histórico de saúde do jovem e da família; 5) existência de acompanhamento do jovem ou da família por algum equipamento da rede socioassistencial; 6) existência de cumprimento de medida socioeducativa; e 7) existência de cumprimento de Liberdade Assistida.

Considerando-se as peculiaridades marcantes desse grupo laboral, suas percepções e vivências temporais, o objetivo deste estudo foi analisar e comparar como se configuram as percepções temporais de jovens trabalhadores assistidos pelo ESPRO das cidades de São Paulo (SP) e Curitiba (PR). Para tanto, o referencial teórico deste artigo envolve conceitos de tempo e tempo nas organizações, assim como as dimensões temporais apresentadas por 
Bluedorn e Jaussi (2007) e as peculiaridades dos sujeitos abordados. Após descrever a metodologia da pesquisa, passa-se à apresentação e análise dos dados, seguidas das considerações finais do artigo e das referências utilizadas.

\section{Referencial Teórico}

Nesta seção é apresentada a abordagem teórica que suporta a discussão proposta. Para isso, inicialmente, é discutido o tema tempo nas organizações, expondo, em um segundo momento, as dimensões temporais elencadas por Bluedorn e Jaussi (2007) e utilizadas como principal aporte teórico na pesquisa. Por fim, o grupo de jovens trabalhadores é caracterizado, demonstrando suas peculiaridades.

\subsection{Tempo e Tempo nas Organizações}

O tempo constitui um elemento marcante no cotidiano dos indivíduos e permeado por enigmas, considerando que vida, morte e tempo se combinam de forma intrigante e complexa de ser esclarecida (WHITROW, 2005). Embora seja alvo de estudos das mais diversas áreas de conhecimento, como psicologia, sociologia, antropologia, história, biologia, arte, religião, filosofia e física, sendo nestas duas últimas áreas onde os estudos são mais profícuos (PAIVA et al., 2013; ELIAS, 1998), ainda existem muitos aspectos a serem discutidos sobre o tema (BARBOSA, 2018; MELLO; TONELLI, 2002a), considerando que o tempo é algo fácil de ser entendido de forma intuitiva, desde que ninguém peça para defini-lo e explicá-lo objetivamente (WHITROW, 2005).

A dificuldade na relação com o tempo é uma das características peculiares do mundo moderno, mas isso não significa que a importância dada ao tempo tenha surgido apenas na atualidade (WHITROW, 2005), pois as indagações e estudos que abordam o tempo e seus aspectos existem desde a antiguidade (MELLO; TONELLI, 2002a; LOMBARDI; HANASHIRO, 2010).

Desse modo, as reflexões envolvendo o tempo e a sua complexidade não se restringem a determinados campos de estudo nem a certas esferas da vida dos sujeitos, abrangendo também o campo organizacional (MELLO; TONELLI, 2002a, 2002b; PAIVA et al., 2013). $\mathrm{Na}$ área de Administração, os estudos sobre a temática ainda são uma preocupação mais recente (VERGARA; VIEIRA, 2005). Não obstante, há uma relação entre o tempo e a Administração desde os estudos clássicos da área, como o de Taylor (1970) abordando os tempos e movimentos dos operários e a sua relação com a produtividade individual e organizacional.

O tempo constitui aspecto chave no ambiente organizacional, sendo envolvido em grande parte dos conceitos relacionados à administração, como aqueles relativos à gestão, finanças, estratégias, planejamento, produção e marketing, além do próprio cotidiano dos sujeitos organizacionais, cotidiano esse permeado por crenças e atitudes relativas ao tempo (LOMBARDI; HANASHIRO, 2010). Apesar dessa íntima relação, a evolução dos estudos sobre o tempo na Administração não acompanhou as mudanças da sociedade e não reflete a sua relevância para a área, uma vez que é importante desenvolver "uma reflexão profunda em torno da temporalidade na Administração, seja com estudos qualitativos seja com estudos quantitativos, seja com abordagens críticas seja com abordagens pragmáticas" (MELLO; TONELLI, 2002a, p. 12).

As dificuldades ao tratar de tempo tem início desde o seu conceito, que não tem delimitações claras e unívocas, gerando diferentes classificações e perspectivas relativas ao tema. Como exemplo, temos a tipologia de tempo de Butler (1995), que aborda o tempo cronológico (mensurável), o tempo orgânico (processual e coletivo), o tempo estratégico (político e negociado) e o tempo espasmódico (contraditório e elástico). Já Hassard (2001) 
aborda o tempo cronológico (mensurável), o tempo simbólico (percebido) e o tempo pósmoderno (simultâneo e comprimido). Por sua vez, Jönsson (2004) traz como tipos de tempo: cronológico (mensurável), vivido (experimentado), de lazer (dedicado ao descanso) e tempo de parada (pausa necessária para o indivíduo se organizar antes de iniciar uma tarefa). É possível notar, diante dessas classificações, uma separação entre o tempo objetivo, o tempo representado pelo relógio e pelo calendário; e o tempo conforme aspectos subjetivos, relacionados à sua percepção e vivência.

Diversos autores consideram o tempo uma construção social (CHANLAT, 1996; ELIAS, 1998; BERGER; LUCKMANN, 2004; WHITROW, 2005; LECCARDI, 2005), considerando que nada ocorre alheio ao tempo e ele constitui um meio de orientação indispensável para a vida em sociedade que nos é inculcado desde a infância. Conforme afirmam Berger e Luckman (2004, p. 44), "todo indivíduo tem consciência do fluxo interior do tempo, que por sua vez se funda nos ritmos fisiológicos do organismo, embora não se identifique com estes".

No âmbito das organizações, um dos pioneiros a estudar profundamente a relação entre o tempo e as mudanças acarretadas pelo capitalismo industrial foi Thompson (1991), no artigo "Time, work-discipline and industrial capitalism", que abordou a influência dessas mudanças na percepção de tempo dos trabalhadores e na disciplina no trabalho. Segundo o autor, o controle do tempo e a remuneração com base nele reforçaram a associação de tempo a dinheiro, tornando-o quantificável, mensurável e controlável e, assim, alterando as relações de trabalho.

Nesse sentido, Harvey e Sobral (1994) também associaram as mudanças nas concepções de tempo e espaço ao capitalismo, afirmando que ambos tornaram-se efêmeros e fragmentados e que o sistema capitalista usa-os como controle em prol da obtenção de lucro, considerando que "o dinheiro pode ser usado para dominar o tempo" (HARVEY; SOBRAL, 1994, p.207). Em consonância com Thompon (1991) e Harvey e Sobral (1994), Hassard (2001) fez reflexões sobre o tempo e as organizações dando ênfase ao uso do tempo como controle no sistema capitalista e na percepção do tempo como mercadoria.

Lee e Liebenau (1999), por sua vez, desenvolveram uma pesquisa com o intuito de classificar os estudos relacionados ao tempo nas organizações, enfatizando o conceito utilizado e o papel por ele desempenhado nos estudos. Segundo os autores, embora os trabalhos que envolvem questões temporais sejam relativamente expressivos em número, pois são alvo de interesse de diversas áreas de conhecimento, eles são consideravelmente dispersos e não sistemáticos, sendo o tempo muitas vezes encarado como algo natural e evidente, que não requer problematizações. Nos estudos analisados por eles foram observadas tentativas de distinção entre o "tempo de relógio" e o "tempo social" e, no que tange ao papel do tempo, ele é considerado uma variável independente em alguns estudos, sendo enfatizada a compreensão da influência de fatores temporais no comportamento individual, grupal e organizacional; e uma variável dependente em outras reflexões, que destacam a influência dos aspectos individuais, situacionais e organizacionais na maneira com que os indivíduos entendem e vivenciam o tempo (LEE; LIEBENAU, 1999).

Seguindo essa mesma linha, Mello e Tonelli (2002a) analisaram como o tempo vem sendo tratado na produção acadêmica de estudos organizacionais, considerando sete periódicos internacionais da área no período de 1986 a 2001. Nesse período, foram encontrados apenas 49 artigos, dos quais 31 faziam referência ao tempo apenas de forma periférica, indicando escassez de estudos sobre a temática. Como resultado, Mello e Tonelli (2002a) evidenciaram que o tempo é tratado nos estudos organizacionais por meio de discussões não homogêneas, dispersas e não sistemáticas, o que corrobora com os achados de 
Lee e Liebenau (1999), frisando que diversos dos estudos analisados apontam para a necessidade de desenvolvimento de mais pesquisas sobre o tema.

Em levantamento recente sobre os estudos envolvendo o tempo nas organizações, Barbosa (2018) realizou uma pesquisa sobre os artigos publicados envolvendo a temática, no período de 2007 a 2017, através do site Scientific Periodicals Eletronic Library (SPELL). Na busca, foram encontrados 259 artigos que, após uma triagem com base nos títulos e resumos de cada um, foram reduzidos a 26 artigos que tratam diretamente do tempo nas organizações. Dentre eles, 22 são estudos de abordagem qualitativa (sendo sete deles ensaios teóricos), dois de abordagem quantitativa e dois de abordagem quantitativa e qualitativa. Neles, foram focalizados diferentes sujeitos de pesquisa, como docentes, executivos, bancários, gerentes, vigilantes, profissionais que trabalham em shopping centers, restaurantes e panificadoras; contudo, nenhum contempla a realidade dos jovens trabalhadores, indicando que é um grupo carente de ser considerado nos estudos sobre o tempo.

Diante do exposto e das possibilidades que se abrem ao explorar a temática, pode-se afirmar que há espaço para o desenvolvimento de mais estudos sobre o tempo na Administração e que há a necessidade de discuti-lo sob diferentes perspectivas, considerando sua influência no âmbito organizacional.

\subsection{Dimensões Temporais de Bluedorn e Jaussi (2007)}

O tempo pode ser percebido e vivido de formas heterogêneas pelos indivíduos, que desenvolvem suas preferências gerando percepções e entendimentos a seu respeito que não são únicos e consensuais, conforme defendem Bluedorn e Jaussi (2007). O tempo subjetivo destaca-se do tempo objetivo, o que facilmente pode ser constatado ao observar que, em detrimento de o tempo ser, segundo uma visão simplista, o "mesmo para todos", quando os indivíduos estão fazendo alguma atividade que lhes atrai ou provoca emoções positivas, parece que o tempo passa mais rápido, o que não é percebido quando o indivíduo está passando por emoções negativas ou vivenciando atividades que lhes são pouco atrativas (VASILE, 2015).

Discorrendo sobre o tempo e as diferentes percepções que podem ser formadas acerca dele, Bluedorn e Jaussi (2007) elencaram cinco dimensões temporais relacionadas às preferências dos sujeitos ao lidar com o tempo, sendo elas: policronicidade, velocidade, pontualidade, profundidade e, por fim, arrastamento, que se subdivide em três: sincronia, liderança, condução. Os autores trouxeram diversas proposições sobre aspectos individuais, grupais e organizacionais envolvidos nas preferências dos sujeitos em relação às tais dimensões temporais, que produzem impacto no desempenho laboral, nas lideranças, nos relacionamentos e na produtividade da organização (BLUEDORN; JAUSSI, 2007; LOMBARDI; HANASHIRO, 2010).

A policronicidade, destacada como "uma estratégia fundamental para engajar a vida" (BLUEDORN, 2002, p. 48), envolve a preferência do sujeito, consciente ou inconsciente, de se envolver em uma ou diversas atividades simultaneamente, sendo relevante frisar que isso não necessariamente se refere a realizar as atividades ao mesmo tempo, como dirigir e falar ao celular, por exemplo, mas que essas atividades são realizadas de forma intercalada ou sobreposta, no mesmo período de tempo. A preferência em relação à policronicidade envolve um contínuo, com graus diferenciados, em que em uma extremidade estão as pessoas policrônicas, que preferem se envolver em atividades diversas simultaneamente e, na outra, estão as pessoas monocrônicas, que preferem chegar ao fim de uma tarefa para então se engajar em outra (BLUEDORN; JAUSSI, 2007).

Reconhecendo a importância das demais dimensões temporais listadas por Bluedorn e Jaussi (2007) e também por demais autores, Bluedorn e Jaussi (2007) destacam a 
policronicidade como a mais importante, pois ela está relacionada a um aspecto chave do trabalho, a variedade de habilidades e competências requeridas ao executar uma tarefa. Esta dimensão, segundo os autores, se encontra positivamente relacionada com a tolerância à ambiguidade e com a satisfação no trabalho diante de altos níveis de variedade de habilidades, envolvendo não só o trabalho, mas também outras esferas da vida.

A segunda dimensão temporal, velocidade, se refere à frequência ou ao número de atividades realizadas em uma unidade de tempo (BLUEDORN, 2002). Também se relaciona a um contínuo com graus diferenciados, no qual as pessoas podem desenvolver preferências relativas às extremidades "rápido" e "lento". Alguns aspectos podem influenciar a preferência dos sujeitos em relação à velocidade no âmbito laboral, como os traços de personalidade que possuem (impulsividade e disposição a assumir riscos); a cultura do grupo, indústria e país dos quais a organização faz parte; o tamanho e a estrutura organizacional; e os mecanismos de recompensa financeira. A interligação das duas primeiras dimensões temporais resulta em uma matriz de comportamento que envolve quatro tipos: monocronia acelerada, relacionada à velocidade alta e monocronia alta; monocronia metódica, relacionada à velocidade baixa e baixa monocronia; policronia acelerada, ligada à alta velocidade e alta policronia; e policronia clássica, ligada à baixa velocidade e alta policronia (BLUEDORN; JAUSSI, 2007).

A terceira dimensão temporal diz respeito à pontualidade, envolvendo a preferência do sujeito por estar ou não no "tempo certo", cumprindo horários, prazos, metas e compromissos. Essa dimensão pode ser entendida como a mais objetiva e mensurável, sendo passível de determinação e controle por meio de relógios e calendários, mas traz fortemente a questão da construção social, em que, em determinadas sociedades, o estar no "tempo certo" é diferente do que é em outras. Pontualidade e velocidade estão relacionadas em nível individual, organizacional e nacional (BLUEDORN; JAUSSI, 2007), considerando que a velocidade influencia na finalização e entrega das tarefas.

Profundidade temporal é a quarta dimensão elencada, referindo-se à distância temporal considerada pelo indivíduo entre passado e futuro, para se posicionar frente aos acontecimentos do presente. Conforme distinguem Bluedorn e Jaussi (2007, p. 206), a profundidade temporal "inclui as distâncias combinadas no passado e futuro (profundidade temporal total); no entanto, também é permitido falar de 'profundidade temporal futura' ou 'profundidade temporal passada', se um desses reinos temporais é o principal tema de interesse". Esta dimensão tende a envolver maior dificuldade no sentido da complexidade de racionalizar uma preferência em relação à profundidade temporal (BARBOSA, 2018; PAIVA et al., 2013), principalmente em função da compressão tempo-espaço crescente na vida moderna (BAUMAN, 2007), que torna o passado muito distante e o futuro muito incerto.

A quinta e última dimensão temporal é o arrastamento, no qual se fazem nítidas as relações de poder e sua influência na vivência do tempo. $\mathrm{O}$ arrastamento se relaciona ao ajustamento do ritmo ou do passo a outra atividade ou a outrem (BLUEDORN; JAUSSI, 2007), que pode ocorrer de três formas: sincronia, na qual os ritmos são correspondentes (ex.: músicos de uma orquestra); liderança, na qual o ritmo mais poderoso ou "arrastante" influencia o ritmo "arrastado" a ocorrer antes dele (ex.: estabelecimento de deadlines); e condução, na qual o ritmo mais poderoso leva o "arrastado" a ocorrer depois dele (ex.: sinal sonoro das escolas).

Diante das diferentes percepções que podem ser desenvolvidas no que concerne ao tempo e às dimensões temporais expostas, variando conforme características como gênero, cultura, posição social, posição hierárquica nas organizações e idade (PAIVA et al., 2011), a seguir passa-se ao aprofundamento acerca do grupo abordado na pesquisa, os jovens trabalhadores. 


\subsection{Jovens trabalhadores}

Representando cerca de um terço da população total brasileira, os jovens constituem uma parcela significativa para o desenvolvimento do país (UNFPA, 2010). Em meados dos anos 2000, as taxas de desemprego em relação aos jovens e à população em geral diminuíram, houve aumento da renda e maior formalização do mercado de trabalho. Não obstante, ainda existem grandes desafios para os jovens nessas áreas (VENTURI; TORINI, 2014) e as dificuldades vêm ganhando destaque considerando que "trata-se de um problema social que repercute nos modos de ser de uma geração" (WICKERT, 2006, p. 268).

Definir a juventude não é uma tarefa fácil devido aos critérios históricos e culturais que devem ser considerados. Dessa forma, surgem diversas concepções sobre o que caracteriza a juventude, sendo ela entendida, por vezes, como uma fase de transição entre a infầncia e a vida adulta, na qual o jovem é um "vir a ser", ou como um tempo de liberdade e de expressão de comportamentos exóticos, no qual o jovem transita entre o ensaio e o erro, ou ainda como um momento de crise, marcado pelos conflitos de formação da identidade e personalidade, no qual o jovem busca orientações para sua constituição. Independentemente da perspectiva, "a juventude constitui um momento determinado, mas não se reduz a uma passagem; ela assume uma importância em si mesma" (DAYRELL, 2003, p. 42).

Assim, as diversidades regionais, culturais, sociais e educacionais do contexto dos jovens devem ser consideradas, não sendo possível pensar a juventude em sentido totalmente homogêneo e singular, mas no sentido de juventudes que envolvem grupos heterogêneos (DAYRELL, 2003; VELHO; DUARTE, 2010; VERIGUINE; BASSO; SOARES, 2014). Nesse sentido, Mesquita, Júnior e Simões (2012, p. 39) afirmam que "os jovens, como todos os grupos sociais, sofrem influências e influenciam os contextos sociais, econômicos, políticos e culturais nos quais se inserem", sendo o mercado de trabalho um locus em que muitas dessas influências podem ser notadas e devem ser alvos de reflexão e intervenção.

$\mathrm{O}$ trabalho em relação à juventude configura "um importante espaço de socialização, aprendizado e discussão das responsabilidades e modos de agir e de pensar na vida adulta, além de ser o local no qual aprendem muitas das estratégias que irão utilizar no futuro, enquanto trabalhadores" (OLIVEIRA, 2011, p. 91). Contudo, as dificuldades de inserção e manutenção no mercado de trabalho marcam o contexto laboral do jovem, cabendo destacar que a discriminação em função da idade ocorre de forma sistemática no mundo laboral (ANGUS; REEVE, 2006).

Os jovens sofrem pressões, inclusive de si mesmos, para ingressarem no mercado de trabalho, tornarem-se trabalhadores e descobrirem aquilo com o que se identificam, dando um "rumo" à vida. Não obstante, as taxas de desemprego são mais altas entre essa parcela da população (REIS, 2015) e os jovens trabalhadores normalmente enfrentam condições laborais ruins, trabalham em ocupações pouco qualificadas, recebem baixa remuneração em contrapartida e enfrentam jornadas de trabalho semanais superiores ao que seria adequado na sua faixa etária (UNFPA, 2010; SILVA, 2015).

Dessa forma, os jovens tendem a vivenciar condições de vulnerabilidade social em relação à inserção e à continuidade profissional (REIS, 2015; WICKERT, 2006), sendo o contexto de trabalho em que se encontram caracterizado como precário e permeado por instabilidade e rotatividade (LOUGHLIN; LANG, 2005; REIS, 2015). Logo, é possível afirmar que os jovens "encontram-se à deriva profissional e agarram-se a quaisquer possibilidades de inserção" (WICKERT, 2006, p. 269). Nesse sentido, cabe destacar a importância de medidas que envolvam o jovem em suas especificidades, respeitando as suas características e as suas formas de interpretar o mundo, para que seja possível "construir espaços de entendimento efetivamente dialógicos, onde a/o jovem possa se tornar agente 
efetivo do próprio desenvolvimento, tratando dos temas que afetam sua vida" (UNFPA, 2010, p. 17).

O trabalho é apenas um desses temas, mas tendo em vista que ele representa parte fundamental das vivências na juventude e pode se configurar como um problema (ou solução) pessoal e socialmente para os jovens, sublinha-se a importância de coloca-lo em pauta (ROCHA et al., 2019). Considerando comprometimento organizacional e percepções temporais de jovens trabalhadores, Rocha et al. (2019) realizaram um estudo com jovens de Recife (PE) e constataram que há correlações significativas entre os construtos, principalmente envolvendo o comprometimento afetivo e as percepções temporais. Além disso, as percepções temporais demonstraram correlação positiva com variáveis como sexo, escolaridade e ramo de atuação; e os jovens analisados demonstraram, em sua maioria, preferências por comportamentos monocrônicos, rápidos e pontuais, com ênfase no passado e arrastados predominantemente por liderança. Neste estudo, Rocha et al. (2019) destacaram a importância de se considerar também jovens de outras cidades brasileiras e suas idiossincrasias.

Diante do exposto, a seguir são descritos os procedimentos metodológicos utilizados na pesquisa de campo que abordou jovens de duas capitais brasileiras, São Paulo (SP) e Curitiba (CR), em relação a suas realidades laborais.

\section{Percurso Metodológico}

A fim de alcançar o objetivo proposto na pesquisa, de analisar e comparar como se configuram as percepções temporais de jovens trabalhadores assistidos pelo ESPRO das cidades de São Paulo (SP) e Curitiba (CR), foram adotados procedimentos metodológicos de natureza quantitativa, permitindo apreender as características gerais de ambos os grupos analisados. Quanto aos meios, a pesquisa utilizou estudo de caso, que constitui um meio de atingir diferentes propósitos, explorando exaustivamente e em profundidade um ou poucos objetos, de forma a conhecê-los de forma ampla e detalhada (GIL, 2008). Quanto aos fins, foi realizada uma pesquisa descritiva, que se caracteriza, principalmente, por descrever as características de populações e fenômenos ou possibilitar o estabelecimento de relações entre variáveis (GIL, 2008).

Os sujeitos da pesquisa foram os jovens trabalhadores assistidos pelo ESPRO, escolhidos devido às peculiaridades que apresentam enquanto jovens e, ainda, pelas características que apresentam em virtude de sua situação de vulnerabilidade socioeconômica. Deste modo, a unidade de análise caracterizou-se pelas percepções temporais destes jovens e a unidade de observação foram os jovens trabalhadores do ESPRO das unidades de São Paulo (SP) e Curitiba (CR). Ressalta-se que as regiões foram escolhidas por critérios de intencionalidade e de acessibilidade, ao passo que as coletas de dados permitissem comparações entre os jovens de diferentes filiais do ESPRO, em diferentes regiões brasileiras. Os jovens participantes deste estudo foram escolhidos tendo por base critérios de acessibilidade e disponibilidade, sendo interpelados nas dependências de três unidades do ESPRO (duas em São Paulo e uma em Curitiba), a partir de autorização das gerências e mediante explicação prévia das finalidades da pesquisa.

Importante sublinhar que o ESPRO é uma instituição sem fins lucrativos, fundada em 1979, que oferece capacitação profissional com vistas à inclusão dos jovens em situação de vulnerabilidade social no mercado de trabalho, sendo "uma das instituições mais engajadas na causa da Aprendizagem no Brasil" (ESPRO, 2016, p. 09). A instituição pauta-se na missão de "promover a inclusão social por meio de ações socioeducativas, mediação de acesso e integração ao mundo do trabalho" (ESPRO, 2016, p. 09). Possui filiais nas cidades de Belo 
Horizonte (MG), Rio de Janeiro (RJ), Brasília (DF), Porto Alegre (RS), Recife (PE), Campinas (SP), Curitiba (PR) e São Paulo (SP), além de diversos polos regionais.

A coleta de dados deu-se presencialmente no ano de 2017, por meio de questionários estruturados fechados, compostos por duas partes: a primeira envolvendo dados sóciodemográficos e profissionais dos jovens respondentes e a segunda referente às percepções temporais dos mesmos. A parte do questionário que diz respeito às percepções temporais foi devidamente validada por Paiva et al. (2013), utilizando como aporte teórico as dimensões temporais de Bluedorn e Jaussi (2007) e contendo 48 perguntas relacionadas às preferências e comportamentos pessoais em relação a tempo e trabalho, em que as respostas são dadas considerando uma escala do tipo Likert de 1 a 6, variando de discordo totalmente a concordo totalmente.

O número de jovens atendidos em São Paulo na época da coleta era de 6.000 e o cálculo amostral, considerando 5\% de significância, retornou o mínimo de 362 questionários. Foram coletados 766 questionários, dos quais 533 foram considerados válidos, superando o mínimo necessário. Em Curitiba, a população era de 784 jovens, sendo 259 o mínimo necessário, dentro dos mesmos padrões estipulados, e foram coletados 561 questionários, dos quais 424 foram considerados válidos, também superando o mínimo necessário. $\mathrm{O}$ tratamento dos dados foi realizado através de métodos estatísticos para efetuar a comparação entre os dados das filiais das cidades consideradas, através das medidas de posição e dispersão obtidas, utilizando estatística descritiva univariada e bivariada. Para a realização e análise dos testes estatísticos, contou-se com o suporte dos programas Microsoft Excel e Statistical Package for the Social Sciences (SPSS 20).

A estatística descritiva univariada possui a vantagem de categorizar o que é típico no conjunto de elementos, por meio das medidas de posição (média, percentis e mediana), além de possibilitar medir como os indivíduos estão distribuídos no conjunto de elementos através das medidas de dispersão (desvio padrão, distribuição de frequência absoluta e relativa) (MATTAR; OLIVEIRA; MOTTA, 2014). Porém, envolve a limitação de trabalhar com cada variável de forma isolada, sendo aconselhado que após sua execução sejam realizados testes estatísticos mais robustos (MALHOTRA, 2001). Sendo assim, foram realizados testes de comparação Mann Whitney, que possuem natureza não paramétrica, tendo em vista o tipo de escala utilizada e o fato de usualmente isso implicar em violação das condições de normalidade da amostra. O Mann Whitney é um teste não paramétrico que possui como vantagem a possibilidade de comparação de duas amostras aleatórias não relacionadas, ou seja, independentes (MALHOTRA, 2001; MATTAR; OLIVEIRA; MOTTA, 2014). Apesar da relevância dos testes estatísticos utilizados, ressalta-se que, pelo fato de a pesquisa quantitativa trabalhar com grande número de casos possui a limitação de não conseguir um maior aprofundamento das razões e motivações subjacentes dos respondentes (CRESWELL, 2007).

\section{Apresentação e Análise dos Resultados}

$\mathrm{Na}$ apresentação e análise dos dados da pesquisa foi descrito inicialmente o perfil sociodemográfico e ocupacional dos jovens trabalhadores respondentes e, em seguida, foram descritas as percepções temporais dos mesmos, com suas medidas de posição e dispersão e os percentuais de respondentes por níveis de análise; realizando-se a comparação entre as filiais de São Paulo e Curitiba.

\subsection{Perfil dos respondentes}

Com relação ao perfil dos jovens trabalhadores respondentes da cidade de São Paulo (SP), a maioria é do sexo feminino, totalizando $60,0 \%$ dos jovens. No que diz respeito à 
idade, a maioria possui de 17 a 19 anos, o que corresponde a 74,5\% dos respondentes, sendo a idade predominante 18 anos (31,9\%). O estado civil mais representativo é solteiro, envolvendo $96,1 \%$ dos jovens; e, no que tange a cor de pele, a maioria se considera branca $(43,7 \%)$ e parda $(30,4 \%)$. A escolaridade dos jovens respondentes é majoritariamente de ensino médio completo $(47,3 \%)$, sendo também representativo o percentual de jovens com ensino superior incompleto $(33,8 \%)$. Em relação à escolaridade dos pais desses jovens, a maioria deles possui ensino médio completo, considerando tanto os pais $(38,6 \%)$, quanto as mães $(38,8 \%)$, porém, é revelada maior escolaridade das mães dos jovens em comparação aos pais, uma vez que apenas $8,3 \%$ dos pais possuem ensino superior completo ou pós-graduação, enquanto $14,1 \%$ das mães possuem tal nível de escolaridade.

Já o perfil dos jovens trabalhadores do ESPRO de Curitiba (PR) envolve majoritariamente jovens do sexo feminino (54,7\%), com idade entre 18 e 20 anos $(57,3 \%)$, sendo a maioria $(26,2 \%)$ com 19 anos. O estado civil predominante é solteiro $(92,2 \%)$ e a cor de pele da maioria é branca $(61,3 \%)$, seguida de parda $(21,7 \%)$. A escolaridade da maioria dos jovens é de ensino médio completo $(46,2 \%)$, com o representativo número de $25 \%$ deles apresentando ensino superior incompleto. Quanto à escolaridade dos pais, a maioria dos pais $(36,6 \%)$ e das mães $(39,6 \%)$ possui ensino médio completo, sendo que as mães tendem a apresentar maior escolaridade, com 13,2\% das mães possuindo ensino superior completo ou pós-graduação e apenas 10,1\% dos pais na mesma situação.

Considerando os dados ocupacionais dos jovens de São Paulo (SP), a maioria deles $(74,7 \%)$ tem tempo de trabalho de até um ano e, considerando o tempo de trabalho na empresa atual, a maioria $(91,3 \%)$ também possui menos de um ano de trabalho. Dos jovens respondentes, 76,0\% afirmam que não procuraram por trabalho nos últimos 30 dias, indicando certa estabilidade dos jovens em relação às empresas nas quais trabalham. Eles estão inseridos, em sua maioria, em bancos, instituições financeiras ou agências de crédito (25\%) e na indústria $(13,9 \%)$, embora $21,6 \%$ não tenha especificado o ramo em que atua. Com relação à renda total dos membros da família dos jovens, a maioria $(55,5 \%)$ possui renda familiar de um a três salários mínimos. Para conseguir trabalho através do ESPRO, 62,9\% dos jovens revelaram que consultaram parentes, amigos ou colegas. Predominou o número de jovens que não realizou cursos do ESPRO anteriormente, como o curso de Formação para o Mundo do Trabalho, totalizando $80,7 \%$ dos respondentes, o que sugere que muitos deles tiveram acesso ao ESPRO através de indicações realizadas por parentes, amigos ou colegas que possuem contatos nas empresas parceiras, que, por sua vez, formalizaram a contratação dos jovens através do ESPRO.

Em relação aos dados ocupacionais dos jovens de Curitiba (PR), majoritariamente $(65,6 \%)$ eles possuem até um ano de trabalho, sendo o tempo de trabalho na empresa atual também inferior a um ano para a maioria deles $(89,9 \%)$. Indicando certa estabilidade na atual empresa, 73,1\% dos jovens não procuraram emprego nos últimos 30 dias. Esses jovens estão inseridos predominantemente no ramo da indústria $(20,8 \%)$ e de instituições financeiras ou agências de crédito $(20,5 \%)$. Considerando a renda total dos membros de suas famílias, a maioria $(66,5 \%)$ tem renda total de um a quatro salários mínimos, sendo a faixa predominante a de dois a três salários $(29,5 \%)$. A maioria dos jovens $(64,6 \%)$ afirmou ter consultado parentes, amigos ou colegas para conseguir uma ocupação formal e, sobre a realização de cursos do ESPRO anteriormente, 58,0\% dos jovens afirmou não ter realizado.

A Tabela 1 expõe, resumidamente, os dados referentes às respostas da maioria dos jovens abordados nas filiais de São Paulo (SP) e Curitiba (PR). 
Tabela 1: Dados sociodemográficos dos respondentes

\begin{tabular}{lllll}
\hline Dados & Cidade & Categoria & $\begin{array}{l}\mathbf{N}^{\mathbf{0}} \text { de } \\
\text { respondentes }\end{array}$ & $\begin{array}{l}\text { \% de } \\
\text { respondentes }\end{array}$ \\
\hline Sexo & São Paulo & Feminino & 320 & 60,0 \\
& Curitiba & & 232 & 54,7 \\
\hline Idade & São Paulo & 18 anos & 170 & 31,9 \\
& Curitiba & 19 anos & 111 & 26,2 \\
\hline Estado civil & São Paulo & Solteiro & 512 & 96,1 \\
& Curitiba & & 391 & 92,2 \\
\hline Cor de pele & São Paulo & Branca & 233 & 43,7 \\
& Curitiba & & 260 & 61,3 \\
\hline Escolaridade & São Paulo & Ensino médio completo & 252 & 47,3 \\
& Curitiba & & 196 & 46,2 \\
\hline Escolar. do pai & São Paulo & Ensino médio completo & 206 & 38,6 \\
& Curitiba & & 155 & 36,6 \\
\hline Escolar. da mãe & São Paulo & Ensino médio completo & 207 & 38,8 \\
& Curitiba & & 168 & 39,6 \\
\hline Renda familiar & São Paulo & De 2 a 3 salários mínimos & 159 & 29,8 \\
& Curitiba & & 125 & 29,5 \\
\hline \multirow{2}{*}{ Tempo trabalho } & São Paulo & Até um ano & 398 & 74,7 \\
& Curitiba & & 279 & 65,6 \\
\hline Ramo empresa & São Paulo & Bancos e instituições financeiras & 133 & 25,0 \\
& Curitiba & Indústria & 88 & 20,8 \\
\hline
\end{tabular}

Fonte: Dados da pesquisa.

De forma sintética, os jovens trabalhadores respondentes de São Paulo e de Curitiba são, em sua maioria, do sexo feminino, entre 18 e 19 anos, solteiros, de cor branca, com ensino médio completo, renda familiar de dois a três salários mínimos e com atuação em bancos e instituições financeiras e na indústria. É interessante notar que os jovens de Curitiba (PR) possuem, de forma geral, faixa etária mais elevada do que os jovens de São Paulo (SP), em que 54\% dos jovens curitibanos possuem 19 anos ou mais e apenas 42,6\% dos jovens paulistas estão na mesma faixa etária; que a cor de pele dos jovens trabalhadores de Curitiba (PR) é expressivamente concentrada em jovens brancos $(61,3 \%)$; e que em ambas as capitais os jovens apresentam percentual significativo de escolaridade referente ao ensino superior incompleto $(33,8 \%$ e $25,0 \%)$.

Após a caracterização do perfil sociodemográfico e ocupacional dos jovens trabalhadores abordados, na seção seguinte são exploradas as características relacionadas às suas percepções temporais.

\subsection{Percepções Temporais dos jovens trabalhadores}

As percepções temporais dos jovens trabalhadores foram analisadas considerando as cinco dimensões temporais de Bluedorn e Jaussi (2007), conforme determinado pela Escala de Percepção Temporal validada por Paiva et al. (2013). A pontuação igual ou superior a 3,5 em cada dimensão indica um comportamento policrônico, rápido e pontual, com profundidade temporal ligada ao futuro e arrastamento temporal relacionado a alguma das subdimensões (sincronia, condução e liderança). As pontuações em cada dimensão abaixo de 3,5 indicam um comportamento monocrônico, lento e não pontual, com profundidade temporal ligada ao passado e sem qualquer ou com menor arrastamento (isto é, comportamento não sincronizado, não conduzido e não liderado). As medidas de posição e dispersão das percepções temporais dos jovens respondentes de São Paulo (SP) e Curitiba (PR) são apresentadas na Tabela 2. 
Tabela 2: Medidas de posição e dispersão de percepções temporais

\begin{tabular}{|c|c|c|c|c|c|c|c|}
\hline & Dimensões & Média & Percepção temporal & p25 & Mediana & p75 & $\begin{array}{l}\text { Desvio- } \\
\text { padrão }\end{array}$ \\
\hline \multirow[t]{8}{*}{ São Paulo } & Policronicidade & 3,68 & Policrônico & 3,30 & 3,70 & 4,00 & 0,531 \\
\hline & Velocidade & 4,04 & Rápido & 3,70 & 4,00 & 4,40 & 0,552 \\
\hline & Pontualidade & 4,78 & Pontual & 4,30 & 4,90 & 5,40 & 0,735 \\
\hline & Profundidade temporal & 3,63 & Futuro & 3,40 & 3,60 & 3,90 & 0,483 \\
\hline & Arrastamento & 4,59 & Com arrastamento & 4,30 & 4,60 & 5,00 & 0,621 \\
\hline & Sincronia & 4,62 & Sincronizado & 4,15 & 4,80 & 5,00 & 0,752 \\
\hline & Condução & 4,27 & Conduzido & 3,80 & 4,30 & 4,80 & 0,687 \\
\hline & Liderança & 4,92 & Liderado & 4,50 & 5,00 & 5,50 & 0,818 \\
\hline \multirow[t]{8}{*}{ Curitiba } & Policronicidade & 3,11 & Monocrônico & 2,70 & 3,10 & 3,50 & 0,561 \\
\hline & Velocidade & 3,68 & Rápido & 3,30 & 3,70 & 4,10 & 0,574 \\
\hline & Pontualidade & 4,57 & Pontual & 4,10 & 4,60 & 5,00 & 0,651 \\
\hline & Profundidade temporal & 2,99 & Passado & 2,80 & 3,00 & 3,30 & 0,518 \\
\hline & Arrastamento & 4,34 & Com arrastamento & 4,00 & 4,30 & 4,70 & 0,544 \\
\hline & Sincronia & 4,36 & Sincronizado & 3,80 & 4,30 & 4,80 & 0,730 \\
\hline & Condução & 4,03 & Conduzido & 3,50 & 4,00 & 4,50 & 0,675 \\
\hline & Liderança & 4,68 & Liderado & 4,30 & 4,80 & 5,20 & 0,693 \\
\hline
\end{tabular}

Fonte: Dados da pesquisa.

A análise das dimensões temporais dos jovens trabalhadores também considerou a distribuição da frequência de cada dimensão, ou seja, a porcentagem de respondentes em cada dimensão temporal, conforme ilustrado no Gráfico 1.

Gráfico 1: Porcentagem de respondentes por nível de análise de dimensões temporais

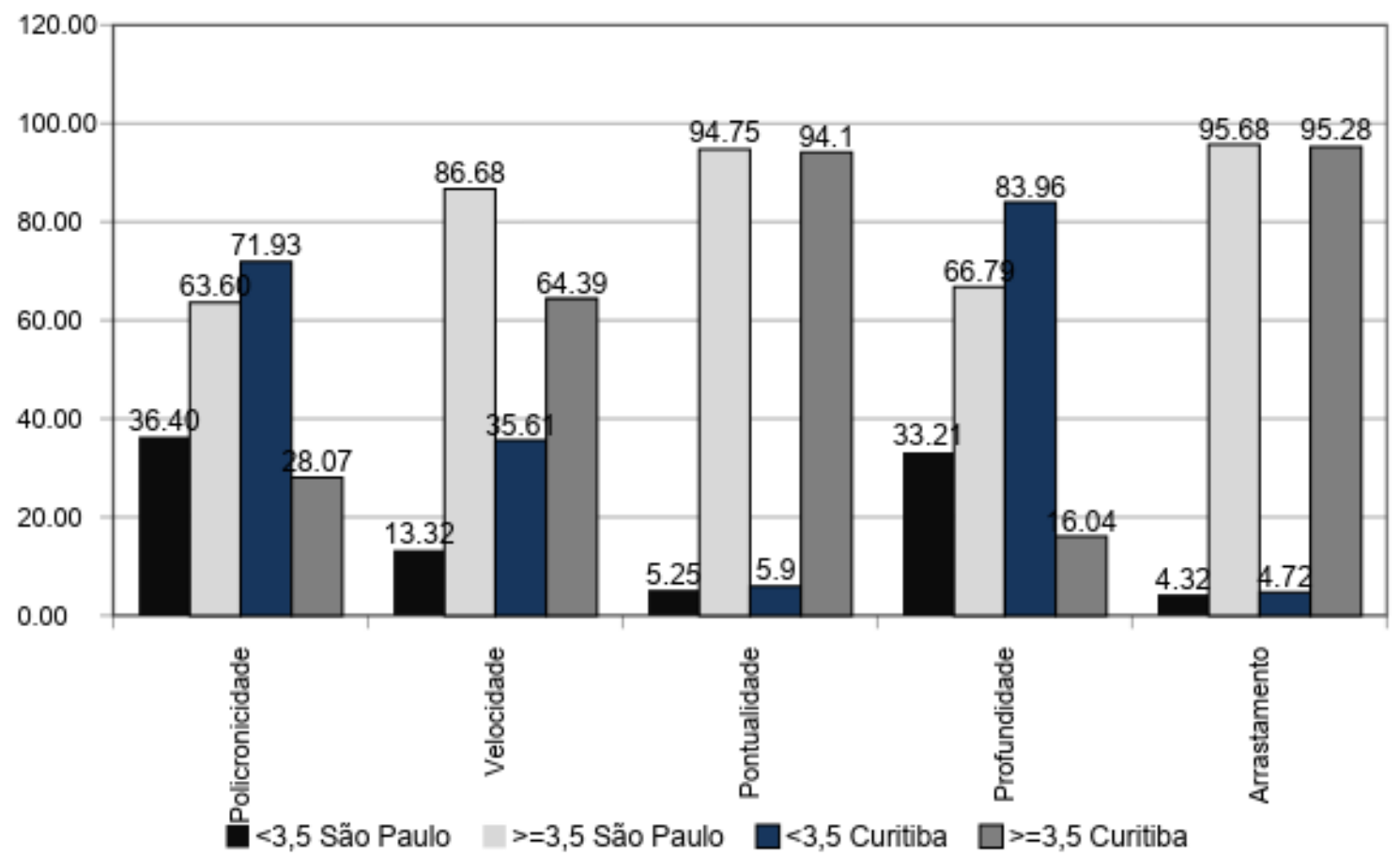

Fonte: Dados da pesquisa.

Analisando os dados obtidos em relação à policronicidade, os jovens de São Paulo apresentaram preferência por comportamentos policrônicos, com média de 3,68 , enquanto os jovens de Curitiba apresentaram preferência por comportamentos monocrônicos, com média de 3,11. Os dados de Curitiba corroboram com Rocha et al. (2019), que afirma haver um 
perfil mais monocrônico entre os jovens, contudo, o panorama de São Paulo contradiz tal afirmação, com 63,6\% dos jovens demonstrando preferência por comportamentos policrônicos. Ressalta-se que, apesar de haver semelhanças no perfil socioeconômico dos jovens atendidos pelo ESPRO, as diferenças encontradas neste estudo têm relação com a existência de diferentes juventudes, perpassadas por aspectos como gênero, etnia, política, cultura, acesso à escolaridade e local de moradia (DAYRELL, 2003; VELHO; DUARTE, 2010; VERIGUINE; BASSO; SOARES, 2014). Nesse sentido, o resultado do teste de comparação, p-valor igual a 0,000, indicou uma diferença estatisticamente significativa entre os grupos, ratificando perfis distintos quanto à policronia dos jovens abordados em cada cidade.

No que tange a velocidade, em ambas as cidades foram encontradas preferências por comportamentos mais rápidos, com média de 4,04 em São Paulo e de 3,68 em Curitiba, embora entre os jovens de São Paulo os comportamentos rápidos sejam mais expressivos $(86,68 \%)$ do que em Curitiba $(64,39 \%)$. Para essa dimensão, o resultado do teste de comparação, p-valor igual a 0,000, também revelou uma diferença estatisticamente significativa entre os grupos, mostrando que, apesar de ambos serem rápidos, os jovens abordados em São Paulo mostraram tendência a serem mais rápidos que os de Curitiba.

Reunindo os dados de policronia e velocidade, tem-se que os jovens trabalhadores paulistas podem ser classificados como policrônicos acelerados, dando preferência a realizar diversas atividades no mesmo período de tempo e de forma rápida; enquanto os jovens trabalhadores curitibanos podem ser classificados como monocrônicos acelerados, apresentando preferência por realizar uma atividade de cada vez e de forma rápida (BLUEDORN; JAUSSI, 2007). Os comportamentos acelerados vão de encontro ao que afirma Tonelli (2008), que chama atenção para a compressão e aceleração do tempo na sociedade contemporânea.

Os dados sobre pontualidade revelaram similaridades nas preferências dos jovens de São Paulo e Curitiba, com médias de, respectivamente, 4,78 e 4,57, sendo as médias mais elevadas dentre as dimensões temporais analisadas nas duas cidades. A preferência dos jovens por comportamentos pontuais pode estar relacionada ao receio que possuem de serem mal avaliados no ambiente laboral, uma vez que comumente os jovens enfrentam dificuldades de inserção e manutenção no mercado de trabalho (WICKERT, 2006; REIS, 2015). Mais uma vez, o resultado do teste de comparação, p-valor igual a 0,000, trouxe uma diferença estatisticamente significativa entre os grupos, pois mesmo sendo pontuais, os jovens pesquisados em São Paulo são mais atentos a esse tipo de limite temporal que os de Curitiba.

Em relação à profundidade temporal, os dados foram discrepantes: a média dos jovens de São Paulo $(3,63)$ indica maior conexão com o futuro e, por outro lado, a média de Curitiba $(2,99)$ indica maior conexão com o passado. Observando os percentuais, tem-se que em São Paulo 66,79\% dos jovens demonstraram comportamento mais ligado ao futuro, enquanto em Curitiba 83,96\% se disseram mais ligados ao passado. Convencionalmente, pode ser esperado que os jovens possuam ligação maior com o futuro, entretanto, eles encontram-se em uma fase de incertezas e inquietações, apresentando diferentes posicionamentos quanto à profundidade temporal, o que pode ser explicado pela complexidade e dificuldade de racionalizar uma preferência em relação a essa dimensão (PAIVA; SOUZA, 2016; BARBOSA, 2018). No caso dessa dimensão, também ficou comprovada uma diferença estatisticamente significativa entre os grupos, já que o resultado do teste de comparação retornou um p-valor igual a 0,000 , ratificando perfis particulares quanto à profundidade temporal dos jovens pesquisados em cada cidade.

A última dimensão analisada foi arrastamento temporal e foram observados os percentuais mais expressivos em relação às demais, tanto em São Paulo $(95,68 \%)$ quanto em 
Curitiba $(95,29 \%)$, como pode ser visto no Gráfico 2, que também permite visualizar as subdimensões do arrastamento.

Gráfico 2: Porcentagem de respondentes por nível de análise do arrastamento temporal

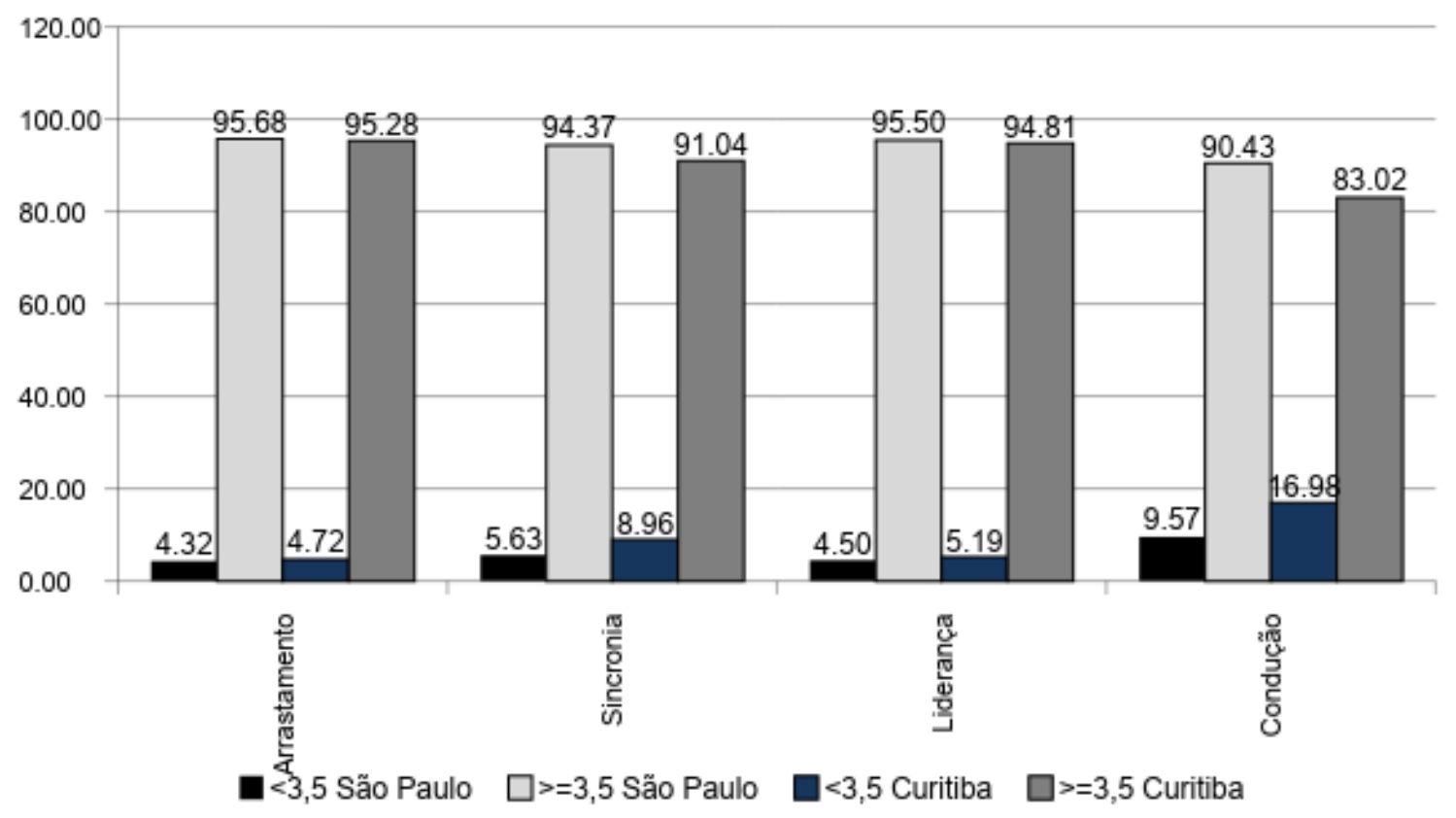

Fonte: Dados da pesquisa.

As médias de arrastamento temporal apresentadas em São Paulo $(4,59)$ e em Curitiba $(4,43)$ constituem dados representativos no que tange às relações de poder que envolvem os jovens trabalhadores, uma vez que o arrastamento é uma dimensão política e coercitiva do tempo (ELIAS, 1998; PAIVA; SOUZA, 2016). Dentre os jovens de São Paulo, 94,37\% se consideram arrastados por sincronia, assim como 91,04\% dos jovens de Curitiba, o que pode ser explicado pela reduzida experiência laboral que possuem, tendendo a seguir ou usar como exemplo aqueles que possuem mais experiência na empresa e no mercado de trabalho.

Em relação à subdimensão liderança, tanto as médias de São Paulo $(4,92)$ e Curitiba $(4,68)$ quanto os seus percentuais, respectivamente, de $95,50 \%$ e $94,81 \%$, foram os mais expressivos entre as subdimensões do arrastamento. Pode-se sugerir que esses achados se justificam pelo desejo dos jovens de serem reconhecidos em seu trabalho, por exemplo, chegando mais cedo em reuniões com seus colegas e superiores (elevada pontualidade) e desempenhando suas tarefas de forma veloz (elevada rapidez), como observado nos dados da pesquisa. Os jovens podem associar comportamentos como esses a demonstrações de responsabilidade e a chances de reconhecimento, ainda que sejam "arrastados" pelos ritmos mais fortes.

No que se refere à última subdimensão, a condução, os percentuais de respondentes por nível de análise também foram expressivos, sendo de 90,43\% em São Paulo e de 83,02\% em Curitiba, contudo, foram os percentuais mais baixos entre as subdimensões do arrastamento. As ações dos colegas e superiores e as rotinas das organizações onde eles estão inseridos podem funcionar como um "gatilho" para o desempenho de suas atividades, constituindo uma relação de condução que é comum no ambiente organizacional, considerando que os gerentes e superiores tendem a promover coesão social e alinhamento dos subordinados às suas preferências temporais e às demandas das organizações (PAIVA; 
SOUZA, 2016).

Por fim, os resultados dos testes de comparação para o arrastamento, de modo geral e para todas as três subdimensões, retornaram p-valores iguais a 0,000 , indicando diferenças estatisticamente significativas entre os grupos, podendo-se concluir que os jovens abordados em São Paulo são mais arrastados temporalmente, em todas as perspectivas, que os de Curitiba.

De forma geral, os dados permitiram estabelecer um panorama das preferências em relação às dimensões temporais elencadas por Bluedorn e Jaussi (2007), observando que há uma consonância entre São Paulo e Curitiba no que diz respeito à velocidade, pontualidade e arrastamento. Por outro lado, os dados demonstraram discrepâncias consideráveis quanto à policronicidade e à profundidade temporal dos jovens atendidos no ESPRO das cidades analisadas. As diferenças podem ser creditadas às peculiaridades de cada região, uma vez que as dimensões temporais são influenciadas pela cultura das organizações e das regiões onde essas organizações e esses jovens se localizam, além de demais peculiaridades relacionadas a gênero, etnia, local de moradia, acesso à escolaridade e outros aspectos a serem alvo de estudos futuros.

\section{Considerações Finais}

A pesquisa desenvolvida neste artigo teve como objetivo analisar e comparar como se configuram as percepções temporais de jovens trabalhadores assistidos pelo ESPRO das cidades de São Paulo (SP) e Curitiba (PR). Buscou-se descrever, analisar e comparar as percepções temporais dos jovens em questão, utilizando como referência as dimensões temporais de Bluedorn e Jaussi (2007). Em termos metodológicos, foi realizada uma pesquisa de natureza quantitativa, descritiva, de campo, desenvolvida através de estudo de caso. A coleta de dados foi feita utilizando questionários e os dados foram tratados por meio de análise estatística descritiva uni e bivariada.

As percepções temporais dos jovens trabalhadores do ESPRO de São Paulo (SP) indicaram comportamentos predominantemente policrônicos, rápidos, pontuais, ligados ao futuro e arrastados. Já em Curitiba (PR), os jovens demonstraram comportamentos predominantemente monocrônicos, rápidos, pontuais, ligados ao passado e arrastados. Dessa forma, foi constatada uma consonância entre São Paulo e Curitiba no que diz respeito à velocidade, pontualidade e arrastamento, enquanto foram percebidas discrepâncias consideráveis relativas à policronicidade e à profundidade temporal. Uma possibilidade é que essas diferenças se devam às peculiaridades regionais, uma vez que as dimensões temporais são influenciadas por aspectos culturais que permeiam os indivíduos, as comunidades onde crescem e vivem e as organizações onde trabalham (PAIVA et al., 2011). São Paulo é uma capital do sudeste comumente associada ao senso de urgência e ao acelerado ritmo de vida no Brasil, conhecida no senso comum como "a cidade que nunca dorme" e Curitiba é uma cidade situada na região sul do país, que possui uma cultura típica devido a aspectos históricos que remontam à colonização regional. As demais peculiaridades que perpassam as juventudes, relacionadas a gênero, etnia, local de moradia e acesso à escolaridade, por exemplo, podem contribuir para as discrepâncias encontradas (DAYRELL, 2003; VELHO; DUARTE, 2010; VERIGUINE; BASSO; SOARES, 2014).

Podem ser mencionadas como contribuições teórico-conceituais da pesquisa o fato de ser um estudo sobre o tempo na área da Administração, visto que, embora seja um tema estudado há muito tempo e em diversas áreas, ainda é pouco explorado no referido campo. Seus achados indicam diferenças interessantes entre os jovens das duas capitais abordadas e merecem aprofundamento em termos de suas naturezas, causas e consequências, tanto individuais como no que tange às organizações por onde tais sujeitos transitam. Além disso, a 
pesquisa coloca em pauta os jovens trabalhadores, chamando atenção à questão da diversidade etária no mundo laboral. Do ponto de vista pragmático-organizacional, a pesquisa contribui com informações que podem auxiliar as organizações na contratação de jovens mais adequados ao tipo de trabalho requerido, auxiliar o ESPRO a realizar um intermédio entre os jovens e as empresas parceiras de forma mais adequada às características de ambos e, ainda, auxiliar os próprios jovens a refletirem sobre sua relação com o tempo e suas vivências no mundo do trabalho.

Como limitações podem ser citadas as características muito específicas dos jovens trabalhadores atendidos pelo ESPRO, que se encontram em situação de vulnerabilidade social e comumente atuam como jovens aprendizes, constituindo um dos níveis mais baixos na pirâmide hierárquica da organização; e a limitação da comparação a apenas duas regiões do Brasil, embora a atuação do ESPRO abranja outras regiões.

Nesse sentido, pesquisas futuras podem abordar jovens de diferentes realidades socioeconômicas e de outras regiões do Brasil, além de jovens assistidos por outras instituições intermediadoras. Sugere-se, ainda, estudos que abordem mais a fundo a questão da profundidade temporal, diante das dificuldades vistas na operacionalização de preferências ou tendências do indivíduo quanto à sua relação com passado, presente e futuro. Nesse sentido, investigações de natureza qualitativa podem ser úteis, assim como para elencar possíveis explicações para as discrepâncias encontradas entre os jovens das regiões consideradas. Por fim, sugere-se a realização de um tratamento estatístico mais sofisticado, tanto de cunho bivariado (com testes de comparação e correlação das dimensões entre si e entre as dimensões e os dados socioeconômicos e profissionais) quanto multivariado (análise fatorial e modelagem de equações estruturais, com vistas à verificação de consistências das dimensões com o público investigado, bem como relações de causa e efeito).

\section{REFERÊNCIAS}

ANGUS, J.; REEVE, P. Ageism: A threat to "aging well" in the 21st century. Journal of Applied Gerontology, v. 25, n. 2, p. 137-152, 2006.

BARBOSA, J. K. D. Temos todo tempo do mundo? Um estudo sobre percepções temporais e prazer e sofrimento com jovens trabalhadores. Dissertação (Mestrado em Administração). Universidade Federal de Minas Gerais, Belo Horizonte, 2018.

BAUMAN, Z. Tempos líquidos. Rio de Janeiro: Jorge Zahar, 2007.

BERGER, P. L.; LUCKMANN, T. A Construção Social da Realidade. Petrópolis: Vozes, 2004.

BLUEDORN, A. C. The Human Organization of Time: temporal realities and experience. Stanford University Press, Stanford, 2002.

BLUEDORN, A. C.; JAUSSI, K. S. Organizationally Relevant Dimensions of time across levels of analysis, In DANSEREAU, F.; YAMMARINO, F. J. (orgs.), Multi-Level Issues in Organizations and Time. Research in multi-level issues - v.6, Elsevier, Oxford, p.187-223, 2007.

BOTELHO, D.M.R. A inserção dos jovens no mercado de trabalho: o caso dos jovens com o ensino secundário. 2016. 74f. Tese (Doutorado em Gestão estratégica de recursos humanos) IPS - Instituto Politécnico de Setúbal, Setubal, 2016.

BUTLER, R. Time in Organizations. Organization Studies, v. 16, n. 6, p. 925-950, 1995.

CHANLAT, J. F. Por uma Antropologia da Condição Humana nas Organizações. In: CHANLAT, J. F. (coord), O Indivíduo na Organização: dimensões esquecidas, p. 21-45, V. I, 3 ed. São Paulo: Atlas, 1996. 
CRESWELL, J. W. Projeto de pesquisa: métodos qualitativo, quantitativo e misto. Porto Alegre: Artmed, 2007.

DAYRELL, J. O jovem como sujeito social. Revista Brasileira de Educação, n. 24, p. 40-52, 2000.

ELIAS, N. Sobre o tempo. Rio de Janeiro: Jorge Zahar Ed., 1998.

GIL, A. C. Métodos e Técnicas de Pesquisa Social. 6. ed. São Paulo: Atlas, 2008.

GRISCI, C. L. I. Trabalho, tempo e subjetividade: impactos da reestruturação produtiva e o papel da psicologia nas organizações. Psicologia: Ciência e profissão, v. 19, n. 1, p. 2-13, 1999.

HARVEY, D.; SOBRAL, A. U. Condição pós-moderna. Edições Loyola, 1994.

HASSARD, J. Imagens do tempo no trabalho e na organização. In: CLEGG, S. R., HARDY, C.; NORD, W. R.; CALDAS, M.; FACHIN, R.; FISCHER, T. Handbook de estudos organizacionais, p. 190-216, v. 2. São Paulo: Atlas, 2001.

JÖNSSON, B. Dez considerações sobre o tempo. Rio de Janeiro: José Olympio Ed., 2004.

LECCARDI, C. Para um novo significado do futuro: mudança social, jovens e tempo. Tempo social, v. 17, n. 2, p. 35-57, 2005.

LEE, H.; LIEBENAU, J. Time in organizational studies: Towards a new research direction. Organization Studies, v. 20, n. 6, p. 1035-1058, 1999.

LOMBARDI, A. R.; HANASHIRO, D. M. M. Policronicidade no ambiente organizacional uma visão conceitual. ENCONTRO NACIONAL DE ESTUDOS ORGANIZACIONAIS EnEO, 6, 2010, Florianópolis. Anais... Florianópolis: ANPAD, 2010.

LOUGHLIN, C.; LANG, K. Young workers. In: In: BARLING, J.; KELLOWAY, E. K.; FRONE, M. R. (eds.), Handbook of work stress, p. 405-430, Thousand Oaks: Sage, 2005.

MALHOTRA, N. K. Pesquisa de Marketing: uma orientação aplicada. 3. ed. Porto Alegre: Bookman, 2001.

MATTAR, F. N.; OLIVEIRA, B.; MOTTA, S. L. S. Pesquisa de Marketing: metodologia, planejamento, execução e análise. Rio de Janeiro: Elsevier, 2014.

MELLO, H. D. A.; TONELLI, M. J. O tempo e as organizações: Concepções do tempo em periódicos de Estudos Organizacionais. Anais do II Eneo, ANPAD, Recife, 2002a.

MELlO, H. D. A.; TONELli, M. J. Tempo é dinheiro? A construção do tempo na administração contemporânea. Anais do XXVI EnANPAD, ANPAD, Salvador, 2002b.

MESQUITA, M. R.; JÚNIOR, G. M.; SIMÕES, A. A. A Juventude brasileira e a educação. Revista Juventude.Br, v. 6, p. 38-46, 2012.

OLIVEIRA, S. R. Ponto de Partida: a juventude e o ingresso no mercado de trabalho. In: Ferraz, D.L.S., Oltramari, A.P., Ponchirolli, O. (org.). Gestão de pessoas e relações de trabalho. São Paulo: Atlas, 89- 112, 2011.

PAIVA, K. C. M.; SOUZA, C. M. O. Time perception: A study of young Brazilian workers. Tourism \& Management Studies, v. 12, n. 1, p. 203-210, 2016.

PAIVA, K. C. M. et al. Proposição de escala de percepção temporal. Encontros CientíficosTourism \& Management Studies, n. 2, p. 523-535, 2013.

PAIVA, K. C. M. et al. Quanto Tempo o Tempo Tem? Um estudo sobre o(s) tempo(s) de gestores do varejo em Belo Horizonte (MG). Organizações \& Sociedade, v.18, n.59, p. 661679, 2011.

POCHMANN, M. A inserção ocupacional e o emprego dos jovens. São Paulo: ABET, 1998. REIS, M. Uma análise da transição dos jovens para o primeiro emprego no Brasil. Revista Brasileira de Economia, v. 69, n. 1, p. 125-143, 2015.

Relatório Anual de Atividades 2015. Disponível em https://issuu.com/esproissuu/docs/relatorio final pdf reduzido?utm source=conversion succ ess\&utm_campaign=Transactional\&utm_medium=email. Acesso em 13/05/2016. 
ROCHA, M. de S.; BARbOSA, J. K. D.; GUIMARÃES, L. R.; PAIVA, K. C. M. Comprometimento organizacional e percepções temporais: um estudo sobre jovens trabalhadores. Teoria e Prática em Administração, v.9, n.1, p. 29-48, 2019.

SILVA, E. R. A. da. (coord.). Juventude e trabalho informal no Brasil. Organização Internacional do Trabalho. Brasília: OIT, 2015.

TAYLOR, F. W. Princípios de administração científica. São Paulo: Atlas, 1970.

THOMPSON, E. P. Time, work-discipline and industrial capitalism. In: Customs in common: Studies in Traditional Popular Culture. London: Merlin Press, p.352-403, 1991.

TOMÁS, M. C.; OLIVEIRA, A. M. H.; RIOS-NETO, E. L. G. Adiamento do ingresso no mercado de trabalho sob o enfoque demográfico: uma análise das regiões metropolitanas brasileiras. Revista Brasileira de Estudos de População, v. 25, n. 1, p. 91-107, 2008.

TONELLI, M. J. Sentidos do tempo e do tempo de trabalho na vida cotidiana. Organizações \& Sociedade, v. 15, n. 45, p. 207-217, 2008.

TUCKER, S.; LOUGHLIN, C. Young workers. In: KELLOWAY, E. K.; BARLING, J.; HURRELL, J. (eds.), Handbook of Workplace Violence, p. 417-444, Thousand Oaks: Sage, 2006.

UNFPA. Direitos da população jovem: um marco para o desenvolvimento. 2d. Brasília: UNFPA - Fundo de População das Nações Unidas. 2010.

VASILE, C. Time perception, cognitive correlates, age and emotions. Procedia - Social and Behavioral Sciences, v. 187, n. 5, p. 695-699, 2015.

VELHO, G.; DUARTE, L. F. D. (org.). Juventude contemporânea: culturas, gostos e carreiras. Rio de Janeiro: 7 Letras, 2010.

VENTURI, G.; TORINI, D. Transições da escola para o trabalho dos jovens homens $e$ mulheres no Brasil. Organização Internacional do Trabalho. Genebra: OIT, 2014.

VERGARA, S. C.; VIEIRA, M. M. F. Sobre a dimensão tempo-espaço na análise organizacional. Revista de Administração Contemporânea, v. 9, n. 2, p. 103-119, 2005.

VERIGUINE, N. R.; BASSO, C.; SOARES, D. H. P. Juventude e Perspectivas de Futuro: A Orientação Profissional no Programa Primeiro Emprego. Psicologia: Ciência e Profissão, v. 34, n. 4, p. 1032-1044, 2014.

WICKERT, L. F. Desemprego e juventude: jovens em busca do primeiro emprego. Psicologia: ciência e profissão, v. 26, n. 2, p. 258-269, 2006.

WHITROW, G. J. O que é o tempo? Uma visão clássica sobre a natureza do tempo. Rio de Janeiro: Jorge Zahar, 2005. 